\title{
Low Capacitance Electrical Probe for Nanoscale Devices and Circuits
}

\author{
Leonard Forbes*, Drake A. Miller** and Michael E. Jacob** \\ *L. Forbes and Associates LLC, PO Box 1716, Corvallis, OR, 97339-1716 USA \\ **Elect. Eng. and Comp. Science., Oregon State University, Corvallis, OR, 97331-5501 USA
}

\begin{abstract}
An electrical probe is constructed of a small capacitor in contact with the circuit node under test so as not to load this circuit node and cause distortion of the input signal. The small capacitor is then placed in series with the small input resistance of a terminated coaxial signal line. The voltage signal at the output of the coaxial line will be approximately the product of the small capacitance, the resistance of the coaxial line and the derivative with respect to time of the input signal. Tungsten probe tips can be sharpened to $100 \mathrm{~nm}$ or less, enabling measurements of nanoscale devices.
\end{abstract}

\section{INTRODUCTION}

In a commonly used measurement techniques the general characteristics of an electrical probe have been to measure a voltage signal. The desirable characteristics of such a probe are: (a) the probe should not influence or "load" the response of the circuit under test; (b) and that it should provide an accurate perhaps attenuated representation of the probed signal over a range of frequencies. This shows that such a voltage signal probe has a high resistance and low capacitance, typical $10 \mathrm{X}$ probes used in state of the art technology divide the voltage under test by using a resistive divider with an adjustable speed up capacitor as shown in Fig. (1). Since the corner frequencies of R-C networks are $f c=1 /(2 \pi R \mathrm{C})$ the resistances are large in the order megohms, and the stray capacitance are picofarads. These types of probes only work up to the $\mathrm{MHz}$ frequencies [1,2]. At higher $\mathrm{GHz}$ frequencies, low impedance $50 \mathrm{ohm}$ probes [3], (Fig. 2), are typically used which is matched to coaxial input lines. The circuit under test will be severely loaded by this small resistance therefore, typically special output drivers are provided to drive these low impedances. Other techniques include probes, with an amplifier at the end of the probe tip [4], with a resistor at the very tip of the probe [5] and those with a high input impedance amplifier in the body of the probe tip [6].

Probing of the internal nodes in integrated circuits $[7,8]$ is often required in trouble shooting designs. Internal circuit probing solutions include electro-optic [9], electron-beam [10], photo-emission [11], and recently scanning probe microscopy (SPM) techniques [12-17]. The SPM probe operates by sensing the electrostatic force induced mechanical deflection of a micro-fabricated probe as it responds to the localized circuit-probe potential difference. Modern integrated circuits are in nanoscale technology with dimensions less than the wavelength of the common optical techniques and dimensions smaller than mechanical deflection probes.

*Address correspondence to this author at the L. Forbes and Associates LLC, PO Box 1716, Corvallis, OR, 97339-1716 USA; Tel: (541) 753-1409; Fax: (541) 753-1409; E-mail: lenforbes@forbes4.com
Tungsten probe whiskers can however still be sharpened to submicron and nanoscale dimensions, the passivation on integrated circuits removed and the tungsten probes placed on internal nodes. These internal nodes however can drive only very small capacitive loads of the order less than $10 \mathrm{fF}$.

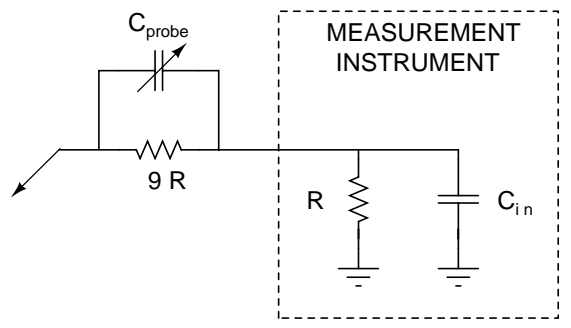

Fig. (1). Typical 10X probe used up to the MHz frequency range.

\section{DESCRIPTION OF THE PROBE}

What is required then is a probe that can measure signals on high frequency nodes in circuits without loading these circuits. This report describes a new probe technique which uses a small, fF, capacitor to differentiate the voltage signal as shown in Fig. (3a). The differentiated voltage signal through the capacitor is a current which is then sensed by a small, typically $50 \mathrm{ohm}$ resistor. This technique works well for large voltage swing high frequency signals on high impedance nodes which can not be loaded by connecting small resistors or impedances. Loading these nodes will cause distortion in the original signal.

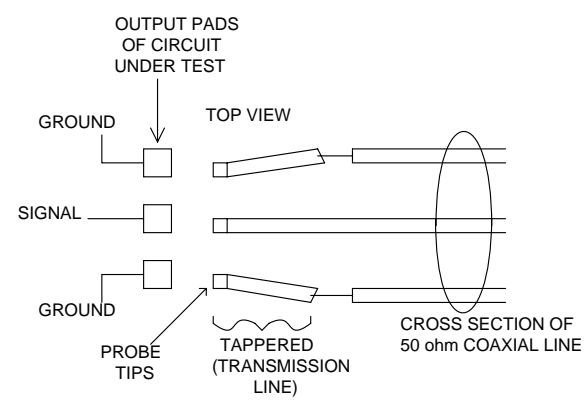

Fig. (2). Conventional microwave probe. 


\section{OPERATION OF THE PROBE}

Fig. (3a) shows the probe elements, a tungsten probe whisker is attached to and separated from an extension of

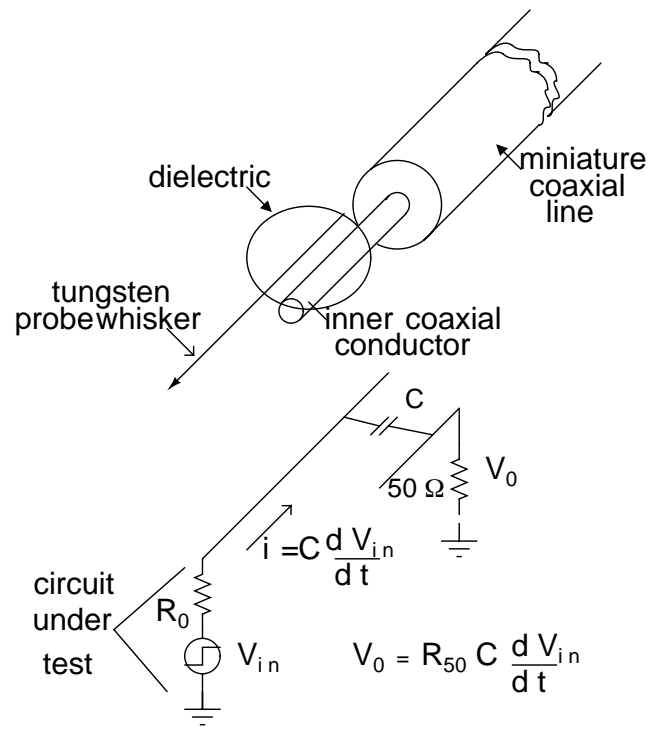

(a) Low frequency model of the low capacitance differentiating probe.

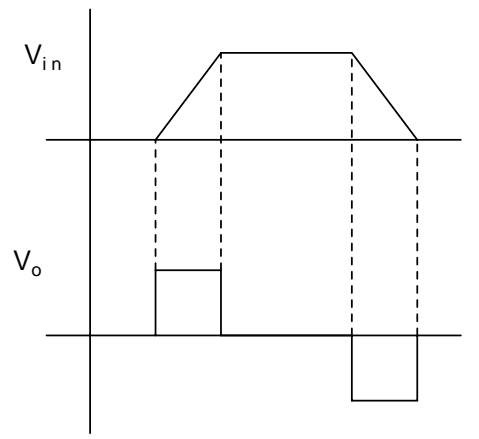

(b) Output of the low capacitance differentiating probe.

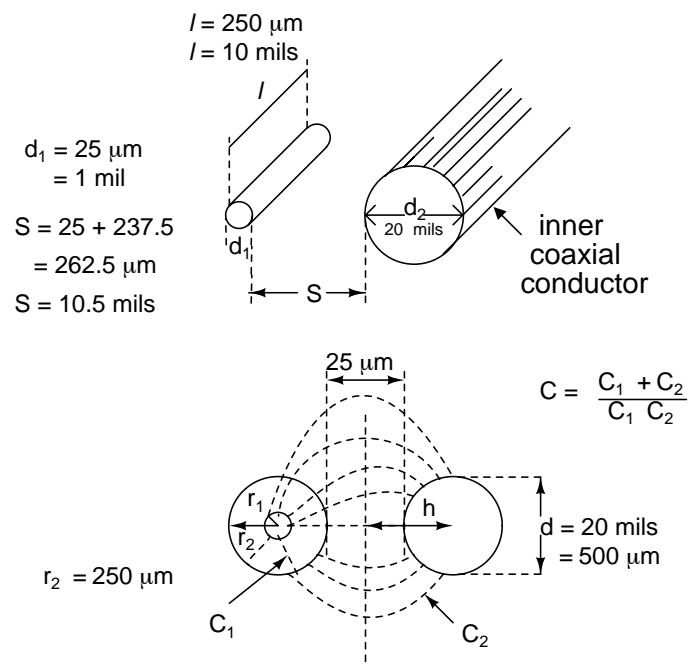

(c) Illustration of calculation of the capacitance of the capacitance probe.

Fig. (3). Differentiating probe. the coaxial line inner conductor by a dielectric epoxy. The miniature coaxial line connects to the signal measuring instruments, in one case this might be a sampling oscilloscope. The technique to be used is described in simple terms at low frequency by Fig. (3b), the output voltage Vo $=\mathrm{R} \mathrm{C} \mathrm{dVin/dt.}$ Where $\mathrm{R}$ is the input impedance of the high frequency coaxial line to the measuring instrument, typically $50 \mathrm{ohms}, \mathrm{C}$ is the small capacitance of the probe touching the circuit node under test, and dVin/dt is the derivative of the voltage, Vin, under test.

Fig. (3c) illustrates a technique to estimate or calculate the capacitance of the low capacitance probe. The formula for the capacitance between two conductors of the same size, $\mathrm{C} 2$, is well known. The smaller cylindrical tungsten whisker probe for the purposes of the calculation is surrounded by an imaginary cylinder of the same size as the coaxial inner conductor. The capacitance between these two cylinders is

$\mathrm{C} 2=\pi \varepsilon \mathrm{r} \varepsilon \mathrm{o} /(\ln (4 \mathrm{~h} / \mathrm{d}))$, where $\varepsilon \mathrm{o}$ is the electric permittivity of free space, er the relative dielectric constant of the material between the cylinders, $\mathrm{d}$ is the diameter of the cylinders and $\mathrm{h}$ is the distance from the center of the cylinders to the mid point between them. The formula for the capacitance of a coaxial line, $\mathrm{C} 1$, is also well known,

$\mathrm{C} 1$ is $=2 \pi \varepsilon \mathrm{r} \varepsilon \mathrm{o} /(\ln (\mathrm{r} 2 / \mathrm{r} 1))$, where $\mathrm{r} 2$ is the radius of the outer cylinder and $\mathrm{r} 1$ is the radius of the inner cylinder, in this case one half is the diameter of the tungsten probe whisker. The capacitance between two conductors of different sizes such as in the probe disclosed here is calculated as the series capacitance of $\mathrm{C} 1$ and $\mathrm{C} 2, \mathrm{C}=\mathrm{C} 1 \mathrm{C} 2 /(\mathrm{C} 1+\mathrm{C} 2)$.

At high frequencies, where the physical dimensions or sizes approach a quarter of a wavelength, $\lambda / 4$ of the frequency, $f$, of the signal under test, then the inductive effects and the sizes of the components become significant. In air which has a relative dielectric constant of one, $\mathrm{f} \lambda=\mathrm{c}$, where, $\mathrm{c}$, is the velocity of light in free space, $3 \times 10^{10} \mathrm{~cm} / \mathrm{sec}$. At 10 $\mathrm{GHz}$ then $\lambda=3 \mathrm{~cm}$ or 1.18 inch.

High frequencies in the $\mathrm{GHz}$ region require inductive effects and components in the circuit model of the probe and transmission line circuit analysis techniques as shown in Fig. (4a). Transmission line circuits can be analyzed by lumped models, where each section of the line, much less than a quarter wavelength long, is represented by the equivalent R,L, C and $G$ elements. Simulation programs or software such as some versions of SPICE $[18,19]$ can solve the corresponding transmission line equations. Normally, the resistance of the line, $\mathrm{R}$, is small and the parallel conductance between lines is small or the lines are lossless and can be represented only by inductive, $\mathrm{L}$, and capacitive, $\mathrm{C}$, elements as in (Fig. (4a)). The tungsten whisker of the probe is coupled to the inner coaxial conductor by both capacitive and inductive effects. The mutual inductive elements, $M$, are modeled in the SPICE program by 'KM' components, where $\mathrm{K}$ indicates the inductive coupling. The coupling between the tungsten whisker and the coaxial inner conductor constitutes a transmission line transformer [20].

Fig. (4) shows the results of a SPICE simulation of a probe such as the one shown in Figs. (4a) and (4b) illustrates an input waveform, Vin, and the output waveform. The coaxial line is terminated at the measuring instrument by 50 


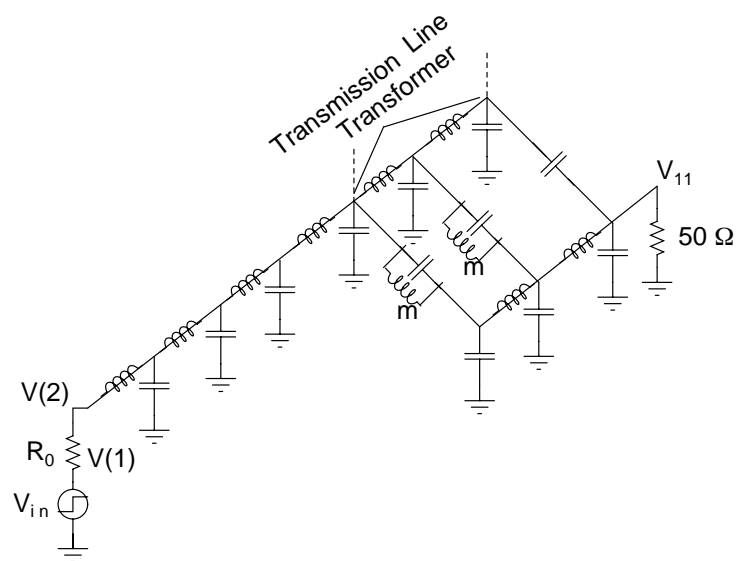

(a) High frequency model of the low capacitance differentiating probe.
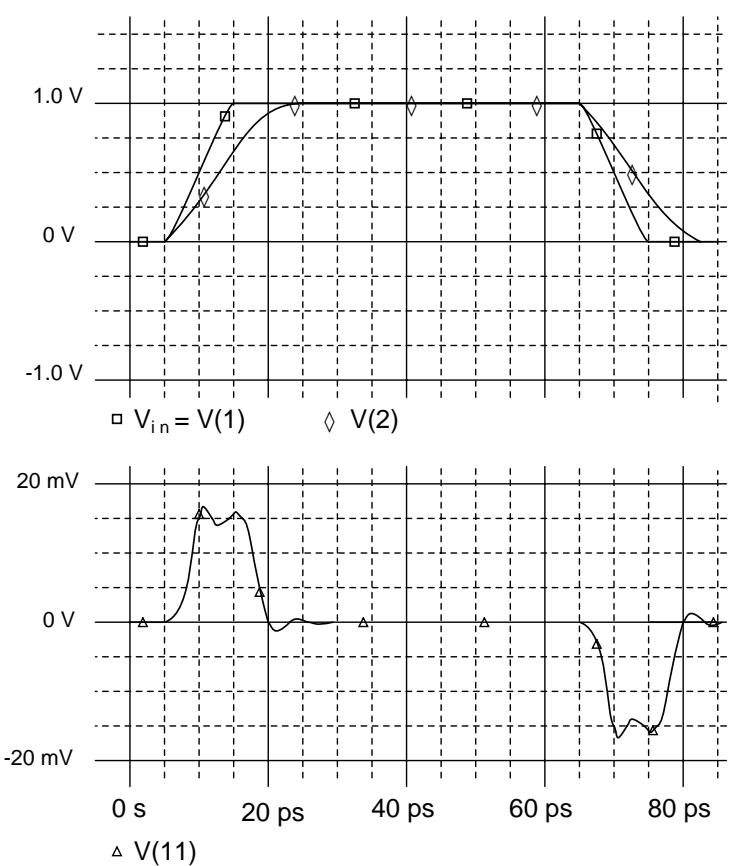

(b) Input square waveform with finite rise and fall times, and simulated output.

Fig. (4). Simulations.

ohms therefor the impedance looking into the coaxial line is a real value or resistance of only $50 \mathrm{ohms}$ at all frequencies. The input waveform has a rise and fall time of 10 picoseconds and a pulse width of 50 picoseconds. The output, corresponds roughly to the derivative of this waveform but includes inductive effects. Knowing the response of the probe or the transfer function from the input with a known waveform to the output one can then solve for the input waveform causing any arbitrary output by using the reciprocal of this transfer function. Such calculations can be done using a program like Matlab available on a personal computer connected to the measuring instruments or incorporated into the measuring instruments.

Fig. (5) shows the results of an input signal used to drive a $50 \mathrm{ohm}$ termination on a test substrate, this is the unknown signal to be measured by the tungsten whisker probe. The signal at the output of the coaxial line, Fig. (5a), is roughly the derivative of this input, and Fig. (5b) is the reconstruction of the signal under test. Fig. (5b) is a square wave illustrating that the unknown test signal can be reconstructed from the waveform data in Fig. (5a). The unknown input was in reality a square wave.

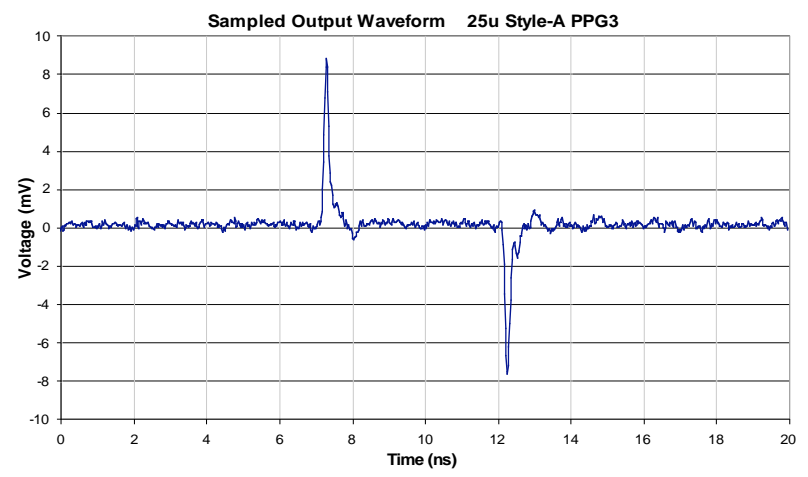

(a) output of the low capacitance probe.

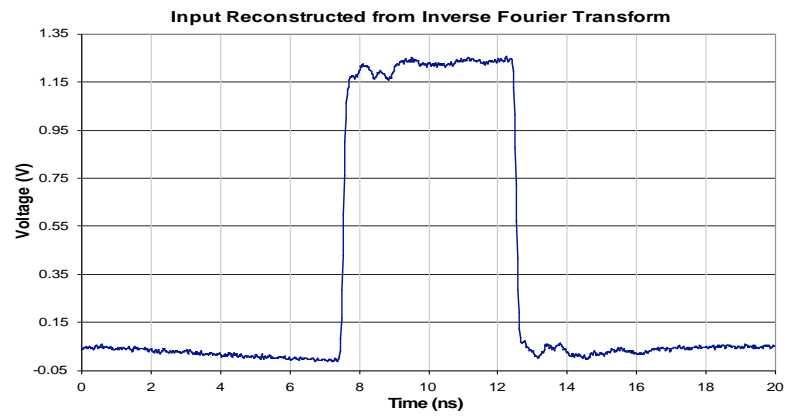

(b) calculation and reconstruction of the input signal from the output of the probe.

Fig. (5). Results.

The technique for characterizing and calibrating the low capacitance probes is shown in Fig. (6). Each probe will be slightly different due to variability in the fabrication and each probe will have a different transfer function. The technique for determining the individual and specific transfer function of each probe is shown in Fig. (6). In Fig. (6) a known signal is generated by a signal generator and measured across a $50 \mathrm{ohm}$ termination at the input to an oscilloscope. This known and well controlled input signal is again generated by terminating a set of low impedance microwave probes [3] on a substrate with test pads and a $50 \mathrm{ohm}$ resistor. This well controlled signal is then sampled with the low capacitive probe, Fig. (6). This same signal is now measured with the low capacitance probe measurement system. The ratio of these two signals, output/input, will be the transfer function of the probe which is unique to that probe. This transfer function can then be used to determine an unknown input waveform from the output signal on an oscilloscope connected to the miniature coaxial line connected to the low capacitance probe.

Alternatively, a network analyzer can be used to more directly determine the transfer function of the probe by meas- 
uring the s-parameters of the probe. The setup is similar to that shown in Fig. (6b).

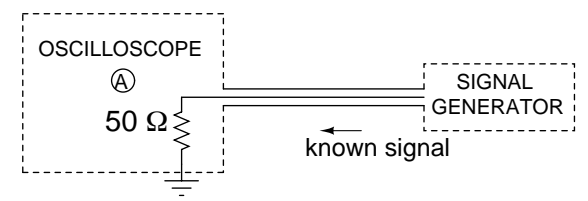

(a) characterization of a "known signal" to be used to calibrate probe

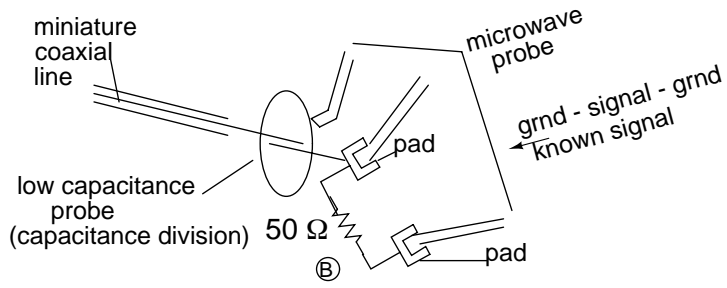

(b) low capacitance probe

Fig. (6). Measurement of a known signal and characterization of the probe.

\section{CONCLUSION}

Many applications in science and electronics require the measurement of high frequency signals and also require that the probe not load the circuit node under test. We have demonstrated here, in Fig. (5), the reconstruction of an unknown input signal and by knowing the transfer function of the probe and using the output signal of the probe.

The differentiating probe disclosed here will enable many new types of design and diagnostic measurements to be made, particularly on nanoscale, devices, integrated circuits, and micro-electrical mechanical systems where a small high impedance probe such as this can probe a small internal node at high frequencies without loading the circuit node.

\section{REFERENCES}

[1] Choosing a Probe, URL http://www.reprise.com/host/tektronix/ reference/ choosing_a_probe.asp (accessed July 21, 2008).

[2] The Oscilloscope, URL https://www.cs.tcd.ie/courses/baict/bac/ jf/labs/scope/setting.html (accessed July 21, 2008).
[3] Burr, J.; Nordgren, G.; Strid, E.W.; Gleason, K.R. Coaxial wafer probe with tip shielding. US Patent 5,565,788, October 15, 1996.

[4] Gleason, K.R.; Jones, K.E. High-frequency active probe having replaceable contact needles. US Patent 5,045,781, September 3, 1991.

[5] Zamborelli, T.J. Wide bandwidth passive probe. US Patent 5,172,051, December 15, 1992.

[6] Crook, D.T.; Heumann, J.M.; McDermid, J.E.; Peiffer, R J.; Schlotzhauer, E.O. Capacitively-coupled test probe. US Patent 5,274,336, December 28, 1993.

[7] Edwards, W. D.; Smith, J. G.; Kemhadjian, H. A. Some investigations into optical probe testing of integrated circuits. Radio Electron Eng., 1976, 46, 35.

[8] Bridges G.E. Non-contact probing of integrated circuits and packages. Microw. Symp. Dig., 2004, 3, 1805.

[9] Yang, K.; Katehi, L.P.B.; Whitaker, J.F. Electric field mapping system using an optical-fiber-based electrooptic probe. IEEE Microw. Wireless Comp. Lett., 2001, 11, 164.

[10] Thong, J. Electron Beam Testing Technology: Microdevices, Physics, and Fabrication Technologies, Plenum, New York, NY, 1993.

[11] McManus, M.K; Song, P. Picosecond imaging circuit analysis of ULSI microprocessors. Proc. IEEE Intl. Microw. Symp., 2002, 1505.

[12] Hou, A.S.; Nechay, B.A.; Ho, F.; Bloom, D.M. Scanning probe microscopy for testing ultrafast electronic devices. J. Opt. Quantum Electron, 1996, 28, 819.

[13] Bridges G.E. Vector-voltage scanning force probe for noncontact MMIC measurement. Electron Lett., 1999, 35, 1724.

[14] Leyk, A.; Kubalek, E. High spatially resolved MMIC-internal millimetre-wave measurements of sinusoidal signals by high frequency electric force microscope-testing. Electron Lett., 1998, 34, 196.

[15] Bridges, G.E.; Said, R.A.; Thomson, D.J. Heterodyne electrostatic force microscopy for non-contact high frequency integrated circuit measurement. Electron Lett., 1993, 29, 1448.

[16] Bohm, C.; Otterbeck, M.; Lipp, S.; Frey, L.; Reuter, R.; Leyk, A.; Mertin, W.; Tegude, F.J. Kubalek, E. Design and characterization of integrated probes for millimeter wave applications in scanning probe microscopy. Dig. IEEE MTT-S Intl. Microw. Symp., 1996, 3, 1529.

[17] Falkingham, C.; Edwards, I.; Bridges, G.E. Non-contact internalMMIC measurement using scanning force probing. Dig. IEEE MTl-S Intl. Microw. Symp., 2000, 3, 1619.

[18] PSPICE by Orcad/Cadence, URL http://www.cadence.com (accessed July $21, \mathbf{2 0 0 8}$ ).

[19] HPICE by Avanti/Synopsys, URL http://www.synopsys.com (accessed July $21, \mathbf{2 0 0 8}$ ).

[20] Sevick J. A simplified analysis of the broadband transmission line transformer. High Frequency Electronics, 2004, 48.

(C) Forbes et al.; Licensee Bentham Open.

This is an open access article licensed under the terms of the Creative Commons Attribution Non-Commercial License (http://creativecommons.org/licenses/by-nc/3.0/) which permits unrestricted, non-commercial use, distribution and reproduction in any medium, provided the work is properly cited. 